ORIGINAL RESEARCH

\title{
Selected Diagnosed Chronic Conditions by Sexual Orientation: A National Study of US Adults, 2013
}

\author{
Brian W. Ward, PhD; Sarah S. Joestl, DrPH; Adena M. Galinsky, PhD; \\ James M. Dahlhamer, PhD
}

\begin{abstract}
Suggested citation for this article: Ward BW, Joestl SS, Galinsky AM, Dahlhamer JM. Selected Diagnosed Chronic Conditions by Sexual Orientation: A National Study of US Adults, 2013. Prev Chronic Dis 2015;12:150292. DOI: http://dx.doi.org/ $10.5888 / \mathrm{pcd} 12.150292$.
\end{abstract}

\section{PEER REVIEWED}

\section{Abstract}

\section{Introduction}

Research is needed on chronic health conditions among lesbian, gay, and bisexual populations. The objective of this study was to examine 10 diagnosed chronic conditions, and multiple $(\geq 2)$ chronic conditions (MCC), by sexual orientation among US adults.

\section{Methods}

The 2013 National Health Interview Survey was used to generate age-adjusted prevalence rates and adjusted odds ratios of diagnosed chronic conditions and MCC for civilian, noninstitutionalized US adults who identified as gay/lesbian, straight, or bisexual, and separately for men and women. Chronic conditions were selected for this study on the basis of previous research.

\section{Results}

Hypertension and arthritis were the most prevalent conditions for all groups. Gay/lesbian adults had a 4.7 percentage-point higher prevalence of cancer than bisexual adults, and a 5.6 percentagepoint higher prevalence of arthritis and a 2.9 percentage point higher prevalence of hepatitis than straight adults. The prevalence of chronic obstructive pulmonary disease was 8.1 percentage points higher among bisexual adults than among gay/lesbian adults and 7.0 percentage points higher than among straight adults. These differences remained in the multivariate analyses. Addition- al differences were found in the sex-stratified analyses. No significant differences were found in MCC by sexual orientation.

\section{Conclusion}

After age adjustment and controlling for sociodemographic characteristics, only a few significant health disparities for diagnosed chronic conditions were found by sexual orientation, and none for MCC. However, for conditions where differences were found, magnitudes were relatively large. Further examination of these differences among gay/lesbian and bisexual adults could yield a better understanding of why these disparities exist.

\section{Introduction}

In recent years, the number of studies that examine health disparities in the United States by sexual orientation increased. Collectively these studies examined various lesbian, gay, and bisexual (LGB), or sexual minority health-related topics, including health risk behaviors (1-6), health care access (4-6), and health care service utilization (2,5-8). However, additional research is not only warranted but needed in numerous areas, one of which is the examination of chronic health conditions among LGB populations (9).

Although chronic conditions among LGB populations are not completely unexamined, only a few studies explored this topic using nationally representative samples $(10,11)$. Most research on chronic conditions by sexual orientation has been state-level population-based studies generalizable only to the US states in which they were carried out, such as Washington $(2,3,5)$, North Carolina (4), Massachusetts $(6,12)$, or California (13). Conditions examined in these studies include arthritis $(2,5)$, asthma $(3,5,6,11)$, cancer (12), cardiovascular disease $(2,4,6,10,13)$, diabetes $(2,5,6)$, high cholesterol (2), and hypertension $(2,5)$, with results varying depending on the sample used. These studies did not examine whether the conditions co-occurred as multiple $(\geq 2)$ chronic conditions (MCC). Determining the prevalence of MCC among sexual 
minorities is important: one in 4 US adults has MCC $(14,15)$, and recent national initiatives have addressed MCC (16-18). In addition, the care and management of MCC is more costly and complex than that of a single condition (19).

The objective of this study was to use a descriptive epidemiological approach to examine 10 diagnosed chronic conditions and MCC by sexual orientation using a large, nationally representative sample of the civilian, noninstitutionalized US adult population. All chronic conditions selected for this study were included in previous research on MCC $(14,15,17)$; some conditions (ie, hepatitis, chronic obstructive pulmonary disease [COPD], weak/failing kidneys) may not have previously been examined by sexual orientation using nationally representative data.

\section{Methods}

\section{Data source}

Data from the 2013 National Health Interview Survey (NHIS) were used. The NHIS is a multipurpose health survey of US households conducted continuously throughout the year and released annually. It serves as a primary source of health data on the civilian, noninstitutionalized US population. Data collection for the NHIS is conducted using computer-assisted personal interviewing; when necessary, interviewers may complete portions of the interview by telephone $(20,21)$. Data used in this study came from 2 of 4 NHIS modules: the Family Core and the Sample Adult Core. The other 2 modules (Household Composition and Sample Child Core) were not used because they either had no variables needed for our analyses or they had data only on children or adolescents $(<18 \mathrm{y})$. The Family Core questionnaire collects information on all family members. In addition, 1 sample adult ( $\geq 18 \mathrm{y})$ from each participating family is randomly selected to answer the Sample Adult Core questionnaire. All sample adult respondents answer for themselves unless mentally or physically unable to do so, in which case a knowledgeable family member serves as a proxy respondent $(20,21)$.

Data analyzed in this study were collected from 34,557 sample adults and are representative of the US adult civilian, noninstitutionalized population; 571 identified as gay/lesbian, and 233 identified as bisexual. The conditional response rate (number of completed sample adult interviews divided by the total number of eligible sample adults) was $81.7 \%$; the final response rate (product of the conditional response rate and the final family response rate) was $61.2 \%(20,21)$.

\section{Measures}

The chronic conditions selected for this study originally stemmed from the HHS Initiative on Multiple Chronic Conditions Strategic Framework $(16,18)$. This framework has 4 overarching goals, one of which is to "facilitate research to fill knowledge gaps about ... individuals with multiple chronic conditions" (18). All chronic conditions examined in this study were diagnosed conditions determined by survey questions asking adults whether they had ever been told by a doctor or health professional that they had a specific condition. Exceptions to this lifetime diagnosis measure were current asthma (measured as currently being diagnosed with asthma), COPD (measured by ever having been diagnosed with emphysema or COPD or having been diagnosed with chronic bronchitis in the past 12 months), and weak/failing kidneys (having been diagnosed in the past 12 months). Indicator variables for the 10 chronic conditions were the following: cancer (including nonmelanoma skin cancers), hypertension, coronary heart disease (CHD), stroke, COPD, current asthma, diabetes, arthritis (including rheumatoid arthritis, gout, lupus, or fibromyalgia), hepatitis, and weak/failing kidneys. These indicator variables were summed to create a categorical measure for number of conditions present: $0,1,2$ or 3 , and 4 or more (14). Although research on MCC suggests including 20 chronic conditions when measuring number of chronic conditions, data are collected in the NHIS for only the 10 aforementioned conditions $(14,17)$.

Sexual orientation was determined by a survey question that asked, "Which of the following best represents how you think of yourself?" For men, responses were gay; straight, that is not gay; bisexual; something else; and "I don't know the answer." For women, response categories were lesbian or gay; straight, that is not lesbian or gay; bisexual; something else; and "I don't know the answer." Methodological considerations for this survey question are detailed elsewhere (20).

Measures for sociodemographic characteristics used in this study were sex, age group, race/ethnicity, education level, total annual combined family income (taken from the NHIS imputed income data) (22), marital status, place of residence, health insurance status, and employment status.

\section{Statistical analyses}

Although crude estimates would show the actual burden of chronic conditions by sexual orientation among US adults, estimates from the NHIS show that chronic conditions and MCC are strongly and positively associated with age (15), whereas selfidentifying as gay, lesbian, or bisexual is negatively associated with age (7). To help negate any potential influence of age on the comparison of the prevalence of chronic conditions by sexual ori-

\footnotetext{
The opinions expressed by authors contributing to this journal do not necessarily reflect the opinions of the U.S. Department of Health and Human Services, the Public Health Service, the Centers for Disease Control and Prevention, or the authors' affiliated institutions.
} 
entation, the estimates were age-adjusted. Age-adjusted prevalence of selected chronic conditions and number of chronic conditions were estimated for the total adult population and separately for gay/lesbian, straight, and bisexual adults (with those $0.2 \%$ of adults who identified as "something else" and $0.4 \%$ of adults who responded "I don't know the answer" dropped from the denominator). Sex-stratified estimates were also generated. Age-adjustment was performed using the 2000 US Census-projected population using the following 3 age groups: 18-44 years, 45-64 years, and $\geq 65$ years (23). Two-tailed significance tests were used to determine significant differences in the prevalence of chronic conditions among gay/lesbian, straight, and bisexual adults. All prevalence differences discussed were considered significant at the $P<$ .05 level and were not adjusted for multiple comparisons.

In addition to these estimates, multivariate logistic regression analyses were conducted. An indicator of each of the selected diagnosed chronic conditions was regressed on sexual orientation (using "straight" as the reference category) and sociodemographic characteristics. Models were estimated for all US adults and for men and women separately (results not adjusted for multiple comparisons). Because our analyses showed no difference in the prevalence of MCC by sexual orientation, no multivariate analyses were conducted for this outcome.

Analyses were weighted using NHIS survey weights to allow for generalization to the US adult civilian, noninstitutionalized population. Survey design variables were incorporated to account for covariance resulting from the complex cluster sample design of the NHIS using SUDAAN version 10.0.1 (RTI International). Because of the relatively small estimated size of the sexual minority population (2.3\% of adults per NHIS) (7) and the resulting small sample sizes in national surveys, the use of national surveys may yield estimates that require cautious interpretation. Thus, prevalence estimates are reported according to the current standards used by the National Center for Health Statistics, where estimates with a relative standard error (RSE) less than $30.0 \%$ are considered reliable. RSEs are calculated as the standard error of an estimate divided by the estimate itself, multiplied by 100 .

\section{Results}

Approximately $1.6 \%$ of adults identified as gay or lesbian and $0.7 \%$ as bisexual; $48.2 \%$ were men; and $47.1 \%$ were aged 18 to 44 (Table 1). Hypertension and arthritis were the 2 most prevalent chronic conditions among all sexual-orientation groups, all adults, and among men and women separately (Table 2), although confidence intervals for prevalence rates for certain conditions overlap and warrant caution when determining rank order.
Some differences in the age-adjusted prevalence of chronic conditions by sexual orientation were found. In only 2 instances was prevalence higher among straight adults than among sexual minority adults: the prevalence of diabetes was 3.8 percentage points higher among straight women than among gay/lesbian women $(8.3 \%$ vs $4.5 \%)$, and the prevalence of cancer was 5.9 percentage points higher among straight women than among bisexual women $(8.4 \%$ vs $2.5 \%)$.

COPD was more than twice as prevalent among bisexual adults $(12.7 \%)$ than among gay/lesbian adults $(4.6 \%)$ or straight adults $(5.7 \%)$. However, other significant differences showed that gay/ lesbian adults had a higher prevalence of some conditions than other sexual orientation groups had - among adults overall and stratified by sex. For example, the prevalence of arthritis was 5.6 percentage points higher among gay/lesbian adults than among straight adults $(26.7 \%$ vs $21.1 \%)$, and the prevalence of hepatitis was 2.9 percentage points higher among gay/lesbian adults than among straight adults (5.5\% vs $2.6 \%$ ). The sex-stratified analyses showed this pattern also for arthritis among women $(36.3 \%$ for gay/lesbian women vs $24.0 \%$ for straight women; a 12.3 percentage-point difference). This same pattern was also found for cancer and hepatitis among men. Cancer was 5.9 percentage points more prevalent among gay men (13.2\%) than among straight men $(7.3 \%)$; hepatitis was 4.8 percentage points more prevalent among gay men $(7.4 \%)$ than among straight men (2.6\%). Cancer was 4.7 percentage points more prevalent among gay/lesbian adults than among bisexual adults $(9.6 \%$ vs. $4.9 \%)$, and it was more than twice as prevalent among gay men as among bisexual men (13.2\% vs $5.8 \%$ ). Arthritis was more than twice as prevalent among gay/ lesbian women as among bisexual women (36.3\% vs $15.8 \%)$.

After controlling for sociodemographic factors, only some significant differences in diagnosed chronic conditions by sexual orientation remained (Table 3). Gay/lesbian adults had moderately higher odds of arthritis compared with straight adults (adjusted odds ratio $[\mathrm{AOR}]=1.52)$; the same was found for women $(\mathrm{AOR}=$ 2.14). Gay men had higher odds of cancer compared with straight men $(A O R=2.09)$. Higher odds of hepatitis were found for gay/ lesbian adults $(\mathrm{AOR}=2.16)$ compared with straight adults and for gay men compared with straight men $(\mathrm{AOR}=2.86)$. When models were run using the bisexual group as the reference category (data not shown in tables), gay/lesbian adults (AOR $=0.42 ; 95 \%$ confidence interval $[\mathrm{CI}], 0.20-0.90)$ and straight adults $(\mathrm{AOR}=$ $0.50 ; 95 \%$ CI, 0.27-0.91) adults had lower odds of COPD than bisexual adults.

The multivariate analysis showed suppression effects in some instances: significant differences not found in the bivariate analysis were found in the multivariate analysis. In the multivariate analys-

The opinions expressed by authors contributing to this journal do not necessarily reflect the opinions of the U.S. Department of Health and Human Services, the Public Health Service, the Centers for Disease Control and Prevention, or the authors' affiliated institutions. 
is (Table 3), bisexual adults had higher odds of hepatitis compared with straight adults $(\mathrm{AOR}=2.38$; 95\% CI, 1.20-4.75). Bisexual men had higher odds of arthritis (AOR $=2.12 ; 95 \% \mathrm{CI}$, $1.11-4.03)$ and hepatitis (AOR $=5.24$; 95\% CI, 2.08-13.21) compared with straight men.

An examination of the number of chronic conditions found no significant differences among gay/lesbian, straight, and bisexual adults having MCC (either 2 or 3 conditions or $\geq 4$ conditions) (Table 4). Furthermore, no differences were found in the percentages of adults who reported a single condition or no chronic conditions. Thus, accounting for age effects resulted in no significant differences in MCC by sexual orientation.

\section{Discussion}

Age-adjusted estimates showed that among US adults, by sex and by sexual-orientation groups, hypertension was the most prevalent chronic condition, followed by arthritis. For certain conditions, significant differences among gay/lesbian, straight, and bisexual adults were found. The prevalence of cancer was higher among gay/lesbian adults than among bisexual adults (although this difference was not significant in the multivariate analyses), and hepatitis and arthritis were more likely to be found among gay/lesbian adults than among straight adults. The findings on arthritis are consistent with those of 1 study that found a higher likelihood of arthritis among gay/lesbian women compared with straight women (13) but are inconsistent with those of another study, which did not find this difference (2).

Bisexual adults had a higher likelihood of COPD than either gay/ lesbian adults or straight adults. Additional differences by sexualorientation group were found in the sex-stratified analyses. These initial stratified analyses found only 2 instances in which estimates were significantly higher among straight adults than among sexual minority groups: the prevalence of diabetes was higher among straight women than among gay/lesbian women, and the prevalence of cancer was higher among straight women than among bisexual women. However, after controlling for sociodemographic characteristics, these 2 differences were not found; this absence of significant differences for diabetes is consistent with previous research $(2,4,6,24)$. Although previous studies found disparities in cardiovascular disease and symptoms $(2,4,6,13)$ and asthma $(6,24)$ by sexual orientation, others did not $(4,6,24)$. Our study found no differences in CHD or asthma prevalence by sexual orientation among all adults or among men and women separately. In addition, no differences in the prevalence of MCC were found by sexual orientation among all adults or among men and women separately.
Although the number of significant differences found was not large, the magnitude of some of these differences was large, and remained even after controlling for sociodemographic variables. For example, COPD was more than 2 times as prevalent among bisexual adults as it was among gay/lesbian or straight adults. The significant differences were also large in magnitude in the sexstratified analyses; for example, gay/lesbian women were twice as likely to have arthritis as bisexual women. Thus, although the number of differences in diagnosed chronic conditions by sexual orientation may be small, the size of these disparities is notable and warrants further examination.

This study has several limitations. The NHIS captures data only on conditions diagnosed by a physician or other health professional; underestimations may result from not including conditions that are not diagnosed. Underestimation may be further compounded in this study because sexual minority groups may have less access to health care (7) and subsequently may be more likely to have undiagnosed chronic conditions. In addition, because NHIS data are mainly self-reported, underreporting may result from a lack of respondent recall. Mental health conditions (ie, depression, substance use disorders), which in recent years are more frequently considered along with physical chronic diseases when studying comorbidities, were not included in this study. Furthermore, only 10 chronic conditions were examined. Although this number is in line with the operational definition of MCC outlined by Goodman and colleagues (17), it only begins to cover the range of chronic conditions among adults in the United States, and it does not include several conditions for which prevalence differs by sexual orientation (eg, HIV, obesity) (7). From a measurement perspective, potential limitations were the small sample sizes of sexual minority groups, which in some instances resulted in unreliable prevalence estimates and wide confidence intervals, and the omission of ascertaining other sexual and gender-minority groups, for example, those identifying as transgender (20). Multiple comparisons were made in this study, which increased the possibility of committing type I errors. Finally, although the NHIS adjusts its sampling weights for nonresponse, a final response rate of $61.2 \%$ for the NHIS Sample Adult Core may also be a limitation.

Nevertheless, this descriptive study may be the first nationally representative examination focused solely on diagnosed chronic conditions and MCC among sexual minority groups, and for some conditions (eg, hepatitis, COPD, weak/failing kidneys), our prevalence estimates may be the first national estimates. Where disparities were found, future research could investigate underlying causes. For example, health and sociodemographic characteristics, such as health-risk behaviors, health care access, care management, or use of health care services, may explain the large differences by sexual orientation in the prevalence of COPD, cancer,

\footnotetext{
The opinions expressed by authors contributing to this journal do not necessarily reflect the opinions of the U.S. Department of Health and Human Services, the Public Health Service, the Centers for Disease Control and Prevention, or the authors' affiliated institutions.
} 
and arthritis. Furthermore, numerous additional chronic conditions, such as liver disease and other types of cardiovascular disease, including angina pectoris and myocardial infarction, are yet to be explored for differences by sexual orientation using NHIS data. Only by further researching chronic conditions among sexual minority populations can a better understanding of disparities (or lack of disparities, as for MCC) be achieved.

\section{Acknowledgments}

No financial support was received for this article. The views expressed in this manuscript belong to the authors and do not necessarily represent the official views of the National Center for Health Statistics, Centers for Disease Control and Prevention, or US Department of Health and Human Services.

\section{Author Information}

Corresponding Author: Brian W. Ward, PhD, National Center for Health Statistics, 3311 Toledo Rd, Hyattsville, MD 20782. Telephone: 301-458-4568. E-mail: bwward@cdc.gov.

Author Affiliations: Sarah S. Joestl, Adena M. Galinsky, James M. Dahlhamer, National Center for Health Statistics, Hyattsville, Maryland.

\section{References}

1. Mays VM, Yancey AK, Cochran SD, Weber M, Fielding JE. Heterogeneity of health disparities among African American, Hispanic, and Asian American women: unrecognized influences of sexual orientation. Am J Public Health 2002; 92(4):632-9.

2. Fredriksen-Goldsen KI, Kim H-J, Barkan SE, Muraco A, HoyEllis CP. Health disparities among lesbian, gay, and bisexual older adults: results from a population-based study. Am J Public Health 2013;103(10):1802-9.

3. Kim HJ, Fredriksen-Goldsen KI. Hispanic lesbians and bisexual women at heightened risk for [corrected] health disparities. Am J Public Health 2012;102(1):e9-15. Erratum in: Am J Public Health. 2012;102(2):202.

4. Matthews DD, Lee JG. A profile of North Carolina lesbian, gay, and bisexual health disparities, 2011. Am J Public Health 2014;104(6):e98-105.

5. Dilley JA, Simmons KW, Boysun MJ, Pizacani BA, Stark MJ. Demonstrating the importance and feasibility of including sexual orientation in public health surveys: health disparities in the Pacific Northwest. Am J Public Health 2010;100(3):460-7.
6. Conron KJ, Mimiaga MJ, Landers SJ. A population-based study of sexual orientation identity and gender differences in adult health. Am J Public Health 2010;100(10):1953-60.

7. Ward BW, Dahlhamer JM, Galinsky AM, Joestl SS. Sexual orientation and health among U.S. adults: national health interview survey, 2013. Natl Health Stat Report 2014; 77(77):1-10.

8. Boehmer U, Miao X, Linkletter C, Clark MA. Adult health behaviors over the life course by sexual orientation. Am J Public Health 2012;102(2):292-300.

9. Institute of Medicine. The health of lesbian, gay, bisexual, and transgender people: building a foundation for better understanding. Washington (DC): National Academies Press, 2011.

10. Farmer GW, Jabson JM, Bucholz KK, Bowen DJ. A population-based study of cardiovascular disease risk in sexual-minority women. Am J Public Health 2013; 103(10):1845-50.

11. Blosnich JR, Lee JGL, Bossarte R, Silenzio VMB. Asthma disparities and within-group differences in a national, probability sample of same-sex partnered adults. Am J Public Health 2013;103(9):e83-7.

12. Landers SJ, Mimiaga MJ, Conron KJ. Sexual orientation differences in asthma correlates in a population-based sample of adults. Am J Public Health 2011;101(12):2238-41.

13. Boehmer U, Miao X, Linkletter C, Clark MA. Health conditions in younger, middle, and older ages: are there differences by sexual orientation? LGBT Health 2014; $1: 168-76$.

14. Ward BW, Schiller JS. Prevalence of multiple chronic conditions among US adults: estimates from the National Health Interview Survey, 2010. Prev Chronic Dis 2013; 10:E65.

15. Ward BW, Schiller JS, Goodman RA. Multiple chronic conditions among US adults: a 2012 update. Prev Chronic Dis 2014;11:E62.

16. Department of Health and Human Services. HHS initiative on multiple chronic conditions. http://www.hhs.gov/ash/ initiatives/mcc/. Accessed September 25, 2014.

17. Goodman RA, Posner SF, Huang ES, Parekh AK, Koh HK. Defining and measuring multiple chronic conditions: imperatives for research, policy, program, and practice. Prev Chronic Dis 2013;10:120239.

18. Parekh AK, Goodman RA, Gordon C, Koh HK;HHS Interagency Workgroup on Multiple Chronic Conditions. Managing multiple chronic conditions: a strategic framework for improving health outcomes and quality of life. Public Health Rep 2011;126(4):460-71.

The opinions expressed by authors contributing to this journal do not necessarily reflect the opinions of the U.S. Department of Health and Human Services, the Public Health Service, the Centers for Disease Control and Prevention, or the authors' affiliated institutions. 
19. Department of Health and Human Services. Multiple chronic conditions: a framework for education and training. Washington (DC): Department of Health and Human Services; 2015.

20. Dahlhamer JM, Galinsky AM, Joestl SS, Ward BW. Sexual orientation in the 2013 National Health Interview Survey: a quality assessment. Vital Health Stat 2 2014;2(169):1-32.

21. National Center for Health Statistics. 2013 National Health Interview Survey (NHIS) public use data release: survey description. Hyattsville (MD): National Center for Health Statistics; 2014.

22. Schenker N, Raghunathan T, Chiu PL, Makuc DM, Zhang GY, Cohen AJ. Multiple imputation of missing income data in the National Health Interview Survey. J Am Stat Assoc 2006; 101(475):924-33.

23. Klein RJ, Schoenborn CA. Age adjustment using the 2000 projected U.S. population. Healthy People 2010 Stat Notes 2001;20(20):1-10.

24. Blosnich JR, Farmer GW, Lee JG, Silenzio VM, Bowen DJ. Health inequalities among sexual minority adults: evidence from ten U.S. states, 2010. Am J Prev Med 2014; 46(4):337-49.

The opinions expressed by authors contributing to this journal do not necessarily reflect the opinions of the U.S. Department of Health and Human Services, the Public Health Service, the Centers for Disease Control and Prevention, or the authors' affiliated institutions. 


\section{Tables}

Table 1. Percentage Distribution of Selected Sociodemographic Characteristics of US Adults, National Health Interview Survey, $2013^{a}$

\begin{tabular}{|c|c|}
\hline Characteristic & $\%^{b}(95 \% \mathrm{Cl})$ \\
\hline \multicolumn{2}{|l|}{ Sexual orientation } \\
\hline Gay/lesbian & $1.6(1.4-1.8)$ \\
\hline Straight & $97.2(96.9-97.4)$ \\
\hline Bisexual & $0.7(0.6-0.8)$ \\
\hline Something else & $0.2(0.1-0.3)$ \\
\hline I don't know the answer & $0.4(0.3-0.5)$ \\
\hline \multicolumn{2}{|l|}{ Sex } \\
\hline Male & $48.2(47.5-48.9)$ \\
\hline Female & $51.8(51.1-52.5)$ \\
\hline \multicolumn{2}{|l|}{ Age, y } \\
\hline $18-44$ & $47.1(46.2-47.9)$ \\
\hline $45-64$ & $34.7(33.9-35.4)$ \\
\hline$\geq 65$ & $18.3(17.7-18.9)$ \\
\hline \multicolumn{2}{|l|}{ Race/ethnicity } \\
\hline Hispanic & $15.0(14.4-15.7)$ \\
\hline Non-Hispanic white & $66.1(65.2-66.9)$ \\
\hline Non-Hispanic black & $11.5(11.0-12.1)$ \\
\hline Non-Hispanic Asian & $5.4(5.0-5.8)$ \\
\hline Non-Hispanic other ${ }^{c}$ & $2.0(1.7-2.2)$ \\
\hline \multicolumn{2}{|l|}{ Education level } \\
\hline Less than high school & $13.8(13.2-14.3)$ \\
\hline High school diploma/GED & $26.1(25.4-26.8)$ \\
\hline Some college & $30.9(30.2-31.6)$ \\
\hline Bachelor's degree or higher & $29.2(28.4-30.1)$ \\
\hline \multicolumn{2}{|c|}{ Total annual combined family income, $\$$} \\
\hline$\leq 24,999$ & $22.2(21.5-23.0)$ \\
\hline $25,000-49,999$ & $23.9(23.2-24.6)$ \\
\hline $50,000-74,999$ & $18.6(18.0-19.2)$ \\
\hline$\geq 75,000$ & $35.3(34.4-36.3)$ \\
\hline
\end{tabular}

\section{Married/cohabitating}

Abbreviations: $\mathrm{Cl}$, confidence interval; GED, general educational development.

a Estimates generated using the 2013 National Health Interview Survey Sample Adult data file $(n=34,557)$. Estimates are crude estimates.

b Percentages may not add to 100 because of rounding.

${ }^{\mathrm{c}}$ Includes adults who identified with multiple racial groups.

(continued on next page)

The opinions expressed by authors contributing to this journal do not necessarily reflect the opinions of the U.S. Department of Health and Human Services, the Public Health Service, the Centers for Disease Control and Prevention, or the authors' affiliated institutions. 
(continued)

Table 1. Percentage Distribution of Selected Sociodemographic Characteristics of US Adults, National Health Interview Survey, $2013^{a}$

\begin{tabular}{|c|c|}
\hline Characteristic & $\%^{b}(95 \% \mathrm{Cl})$ \\
\hline No & $40.0(39.2-40.8)$ \\
\hline Yes & $60.0(59.2-60.8)$ \\
\hline \multicolumn{2}{|l|}{ Place of residence } \\
\hline Not in a metropolitan statistical area & $15.2(13.9-16.6)$ \\
\hline Small metropolitan statistical area & $30.9(29.5-32.4)$ \\
\hline Large metropolitan statistical area & $53.9(52.6-55.2)$ \\
\hline \multicolumn{2}{|l|}{ Health insurance status } \\
\hline Private & $62.1(61.3-62.9)$ \\
\hline Public & $17.9(17.3-18.5)$ \\
\hline Other & $3.4(3.1-3.6)$ \\
\hline Uninsured & $16.6(16.0-17.3)$ \\
\hline \multicolumn{2}{|l|}{ Employed in the past 12 months } \\
\hline No & $32.9(32.2-33.6)$ \\
\hline Yes & $67.1(66.4-67.8)$ \\
\hline \multicolumn{2}{|l|}{ Age by sexual orientation, y } \\
\hline \multicolumn{2}{|l|}{ Gay/lesbian } \\
\hline $18-44$ & $54.4(48.8-59.8)$ \\
\hline $45-64$ & $38.1(32.9-43.6)$ \\
\hline$\geq 65$ & $7.5(5.2-10.7)$ \\
\hline \multicolumn{2}{|l|}{ Straight } \\
\hline $18-44$ & $46.8(46.0-47.7)$ \\
\hline $45-64$ & $34.7(33.9-35.4)$ \\
\hline$\geq 65$ & $18.5(17.9-19.1)$ \\
\hline \multicolumn{2}{|l|}{ Bisexual } \\
\hline $18-44$ & $76.1(68.7-82.3)$ \\
\hline $45-64$ & $19.1(13.5-26.2)$ \\
\hline$\geq 65$ & $4.8(2.6-8.6)$ \\
\hline
\end{tabular}

Abbreviations: $\mathrm{Cl}$, confidence interval; GED, general educational development.

a Estimates generated using the 2013 National Health Interview Survey Sample Adult data file $(n=34,557)$. Estimates are crude estimates.

b Percentages may not add to 100 because of rounding.

c Includes adults who identified with multiple racial groups. 
Table 2. Age-Adjusted Prevalence of Selected Diagnosed Chronic Conditions Among Adults, by Sexual Orientation and Sex, United States, $2013^{a}$

\begin{tabular}{|c|c|c|c|c|}
\hline \multirow[b]{2}{*}{ Condition ${ }^{\mathrm{b}}$} & \multicolumn{4}{|c|}{$\%(95 \% \mathrm{Cl})$} \\
\hline & Total & Gay/Lesbian & Straight & Bisexual \\
\hline \multicolumn{5}{|l|}{ All adults } \\
\hline Hypertension & $27.8(27.2-28.3)$ & $26.2(21.7-31.2)$ & $27.8(27.2-28.4)$ & $24.1(17.2-32.7)$ \\
\hline Arthritis & $21.2(20.7-21.8)$ & $26.7(22.1-31.7)^{\mathrm{c}}$ & $21.1(20.6-21.7)^{d}$ & $22.5(15.7-31.0)$ \\
\hline Diabetes & $8.7(8.3-9.0)$ & $6.7(4.6-9.6)$ & $8.7(8.4-9.1)$ & $9.7(5.4-17.0)$ \\
\hline Cancer & $7.9(7.5-8.2)$ & $9.6(7.0-13.0)^{\mathrm{e}}$ & $7.8(7.5-8.2)$ & $4.9(2.5-9.6)^{\mathrm{d}, \mathrm{f}}$ \\
\hline Current asthma & $6.9(6.5-7.3)$ & $8.6(6.4-11.6)$ & $6.8(6.4-7.2)$ & $11.7(7.3-18.2)$ \\
\hline COPD & $5.7(5.4-6.0)$ & $4.6(2.9-7.1)^{\mathrm{e}}$ & $5.7(5.3-6.0)^{\mathrm{e}}$ & $12.7(7.7-20.2)^{c, d}$ \\
\hline CHD & $4.4(4.2-4.6)$ & $2.9(1.8-4.9)$ & $4.4(4.2-4.6)$ & $4.4(1.8-10.1)^{f}$ \\
\hline Hepatitis & $2.6(2.4-2.8)$ & $5.5(3.7-8.2)^{c}$ & $2.6(2.4-2.8)^{d}$ & $11.5(6.6-19.1)$ \\
\hline Stroke & $2.5(2.4-2.8)$ & $1.6(0.8-3.5)^{f}$ & $2.6(2.4-2.8)$ & $-g$ \\
\hline Weak/failing kidneys & $1.7(1.5-1.9)$ & $2.1(0.9-4.9)^{f}$ & $1.7(1.5-1.9)$ & $-g$ \\
\hline \multicolumn{5}{|l|}{ Men } \\
\hline Hypertension & $28.9(28.1-29.8)$ & $25.8(20.2-32.4)$ & $29.0(28.2-29.9)$ & $29.2(19.6-41.1)$ \\
\hline Arthritis & $18.0(17.3-18.7)$ & $17.8(13.0-23.9)$ & $17.9(17.2-18.7)$ & $27.0(18.6-37.4)$ \\
\hline Diabetes & $9.2(8.6-9.7)$ & $8.6(5.4-13.6)$ & $9.2(8.6-9.7)$ & $13.5(6.8-25.1)^{f}$ \\
\hline Cancer & $7.4(6.9-7.9)$ & $13.2(9.3-18.4)^{\mathrm{c}, \mathrm{e}}$ & $7.3(6.8-7.8)^{d}$ & $5.8(2.2-14.2)^{d, f}$ \\
\hline Current asthma & $5.1(4.7-5.6)$ & $7.8(5.1-11.9)$ & $5.0(4.6-5.5)$ & $9.0(3.4-21.2)^{f}$ \\
\hline COPD & $5.0(4.6-5.4)$ & $3.3(1.9-5.8)$ & $4.9(4.5-5.4)$ & $11.0(4.8-23.1)^{f}$ \\
\hline CHD & $5.8(5.4-6.3)$ & $4.2(2.4-7.2)$ & $5.8(5.4-6.3)$ & $7.9(3.2-18.5)^{f}$ \\
\hline Hepatitis & $2.7(2.4-3.1)$ & $7.4(4.6-11.7)^{\mathrm{C}}$ & $2.6(2.3-3.0)^{d}$ & $16.7(9.6-27.4)$ \\
\hline Stroke & $2.6(2.4-3.0)$ & $-g$ & $2.7(2.4-3.0)$ & $-g$ \\
\hline Weak/failing kidneys & $1.6(1.4-1.9)$ & $1.7(0.8-3.9)^{f}$ & $1.6(1.4-1.8)$ & -8 \\
\hline \multicolumn{5}{|l|}{ Women } \\
\hline Hypertension & $26.6(25.9-27.3)$ & $26.4(20.2-33.9)$ & $26.6(25.9-27.4)$ & $17.7(9.8-29.7)$ \\
\hline Arthritis & $24.2(23.4-24.9)$ & $36.3(29.5-43.7)^{\mathrm{c}, \mathrm{e}}$ & $24.0(23.2-24.8)^{d}$ & $15.8(8.7-27.0)^{d}$ \\
\hline Diabetes & $8.2(7.8-8.7)$ & $4.5(2.5-8.0)^{c}$ & $8.3(7.8-8.8)^{d}$ & $-g$ \\
\hline
\end{tabular}

Abbreviations: $\mathrm{CHD}$, coronary heart disease; $\mathrm{Cl}$, confidence interval; COPD, chronic obstructive pulmonary disease.

a Estimates generated using the 2013 National Health Interview Survey Sample Adult data file $(n=34,557)$.

${ }^{b}$ Chronic conditions are listed in descending order of prevalence for all adults (total). Cls for certain conditions may overlap and warrant caution in determining rank order. All conditions were measured as ever having been told by a doctor/health professional, with the exception of current asthma (currently being diagnosed with asthma), COPD (ever having been diagnosed with emphysema or COPD, or having been diagnosed with chronic bronchitis in the past 12 months), and weak/failing kidneys (having been diagnosed in the past 12 months). Age-adjustment was to the 2000 US Census projected population using 3 age groups:

$18-44,45-64$, and $\geq 65$ years.

${ }^{c}$ Prevalence of this condition was significantly different (2-tailed; $\left.P<.05\right)$ from those who identified as straight.

$\mathrm{d}$ Prevalence of this condition was significantly different (2-tailed; $P<.05)$ from those who identified as gay/lesbian.

e Prevalence of this condition was significantly different (2-tailed; $P<.05)$ from those who identified as bisexual.

$f$ Estimates that have a relative standard error (RSE) $>30.0 \%$ and $\leq 50.0 \%$ and should be interpreted with caution.

$\mathrm{g}$ Estimates have an RSE $>50.0 \%$, are considered unreliable, and are not reported.

(continued on next page)

The opinions expressed by authors contributing to this journal do not necessarily reflect the opinions of the U.S. Department of Health and Human Services, the Public Health Service, the Centers for Disease Control and Prevention, or the authors' affiliated institutions. 
(continued)

Table 2. Age-Adjusted Prevalence of Selected Diagnosed Chronic Conditions Among Adults, by Sexual Orientation and Sex, United States, $2013^{a}$

\begin{tabular}{|c|c|c|c|c|}
\hline \multirow[b]{2}{*}{ Condition $^{\mathrm{b}}$} & \multicolumn{4}{|c|}{$\%(95 \% \mathrm{Cl})$} \\
\hline & Total & Gay/Lesbian & Straight & Bisexual \\
\hline Cancer & $8.4(7.9-8.9)$ & $5.7(3.3-9.7)$ & $8.4(8.0-9.0)^{\mathrm{e}}$ & $2.5(1.2-5.3)^{c, f}$ \\
\hline Current asthma & $8.6(8.0-9.1)$ & $9.5(6.2-14.4)$ & $8.5(7.9-9.0)$ & $12.4(7.3-20.4)$ \\
\hline COPD & $6.4(6.0-6.9)$ & $6.0(3.2-11.0)^{f}$ & $6.4(5.9-6.8)$ & $13.6(6.9-25.2)^{f}$ \\
\hline $\mathrm{CHD}$ & $3.2(2.9-3.5)$ & $-g$ & $3.2(2.9-3.5)$ & $-g$ \\
\hline Hepatitis & $2.5(2.3-2.8)$ & $3.4(1.5-7.4)^{f}$ & $2.5(2.3-2.8)$ & $-g$ \\
\hline Stroke & $2.5(2.2-2.7)$ & $2.4(0.9-6.2)^{f}$ & $2.4(2.2-2.7)$ & $-\mathrm{g}$ \\
\hline Weak/failing kidneys & $1.8(1.6-2.1)$ & $-g$ & $1.8(1.6-2.1)$ & $-g$ \\
\hline
\end{tabular}

Abbreviations: $\mathrm{CHD}$, coronary heart disease; $\mathrm{Cl}$, confidence interval; COPD, chronic obstructive pulmonary disease.

${ }^{a}$ Estimates generated using the 2013 National Health Interview Survey Sample Adult data file $(n=34,557)$.

${ }^{b}$ Chronic conditions are listed in descending order of prevalence for all adults (total). Cls for certain conditions may overlap and warrant caution in determining rank order. All conditions were measured as ever having been told by a doctor/health professional, with the exception of current asthma (currently being diagnosed with asthma), COPD (ever having been diagnosed with emphysema or COPD, or having been diagnosed with chronic bronchitis in the past 12 months), and weak/failing kidneys (having been diagnosed in the past 12 months). Age-adjustment was to the 2000 US Census projected population using 3 age groups: $18-44,45-64$, and $\geq 65$ years.

${ }^{c}$ Prevalence of this condition was significantly different (2-tailed; $\left.P<.05\right)$ from those who identified as straight.

$\mathrm{d}$ Prevalence of this condition was significantly different (2-tailed; $P<.05)$ from those who identified as gay/lesbian.

e Prevalence of this condition was significantly different (2-tailed; $P<.05)$ from those who identified as bisexual.

${ }^{f}$ Estimates that have a relative standard error (RSE) $>30.0 \%$ and $\leq 50.0 \%$ and should be interpreted with caution.

Estimates have an RSE $>50.0 \%$, are considered unreliable, and are not reported. 
Table 3. Logistic Regression of Sexual Orientation and Sociodemographic Characteristics on Selected Diagnosed Chronic Conditions Among Adults, United States, 2013

\begin{tabular}{|c|c|c|c|c|c|c|}
\hline \multirow[b]{2}{*}{ Condition $^{\mathrm{b}}$} & \multicolumn{2}{|l|}{ All Adults ${ }^{c}$} & \multicolumn{2}{|l|}{ Men $^{d}$} & \multicolumn{2}{|l|}{ Women $^{d}$} \\
\hline & AOR (95\% Cl) & $P$ Value & AOR (95\% Cl) & $P$ Value & AOR (95\% Cl) & $P$ Value \\
\hline \multicolumn{7}{|l|}{ Hypertension } \\
\hline Straight & 1 [Reference] & - & 1 [Reference] & - & 1 [Reference] & - \\
\hline Gay/lesbian & $0.97(0.73-1.30)$ & .84 & $0.94(0.65-1.37)$ & .76 & $1.08(0.70-1.66)$ & .73 \\
\hline Bisexual & $0.78(0.49-1.23)$ & .29 & $1.03(0.55-1.92)$ & .93 & $0.66(0.34-1.27)$ & .21 \\
\hline \multicolumn{7}{|l|}{ Arthritis } \\
\hline Straight & 1 [Reference] & - & 1 [Reference] & - & 1 [Reference] & - \\
\hline Gay/lesbian & $1.52(1.14-2.05)$ & .005 & $1.07(0.68-1.68)$ & .78 & $2.14(1.45-3.17)$ & $<.001$ \\
\hline Bisexual & $1.05(0.65-1.71)$ & .83 & $2.12(1.11-4.03)$ & .02 & $0.74(0.38-1.44)$ & .37 \\
\hline \multicolumn{7}{|l|}{ Diabetes } \\
\hline Straight & 1 [Reference] & - & 1 [Reference] & - & 1 [Reference] & - \\
\hline Gay/lesbian & $0.95(0.62-1.46)$ & .83 & $1.11(0.65-1.92)$ & .70 & $0.85(0.42-1.72)$ & .65 \\
\hline Bisexual & $0.88(0.46-1.67)$ & .69 & $1.70(0.70-4.13)$ & .24 & $0.46(0.18-1.22)$ & .12 \\
\hline \multicolumn{7}{|l|}{ Cancer } \\
\hline Straight & 1 [Reference] & - & 1 [Reference] & - & 1 [Reference] & - \\
\hline Gay/lesbian & $1.27(0.86-1.87)$ & .24 & $2.09(1.26-3.46)$ & .004 & $0.76(0.40-1.42)$ & .39 \\
\hline Bisexual & $0.86(0.44-1.70)$ & .67 & $0.72(0.25-2.13)$ & .56 & $0.80(0.35-1.83)$ & .59 \\
\hline \multicolumn{7}{|c|}{ Current asthma } \\
\hline Straight & 1 [Reference] & - & 1 [Reference] & - & 1 [Reference] & - \\
\hline Gay/lesbian & $1.32(0.94-1.85)$ & .12 & $1.60(0.96-2.65)$ & .07 & $1.11(0.70-1.76)$ & .66 \\
\hline Bisexual & $1.58(0.95-2.63)$ & .08 & $1.86(0.62-5.58)$ & .27 & $1.53(0.87-2.70)$ & .14 \\
\hline \multicolumn{7}{|l|}{ COPD } \\
\hline Straight & 1 [Reference] & - & 1 [Reference] & - & 1 [Reference] & - \\
\hline Gay/lesbian & $0.87(0.55-1.38)$ & .55 & $0.82(0.41-1.64)$ & .57 & $0.91(0.48-1.72)$ & .77 \\
\hline
\end{tabular}

Abbreviations: AOR, adjusted odds ratio; CHD, coronary heart disease; $\mathrm{Cl}$, confidence interval; COPD, chronic obstructive pulmonary disease; GED, general educational development; MSA, metropolitan statistical area.

a Estimates generated using the 2013 National Health Interview Survey Sample Adult data file $(n=34,557)$.

${ }^{\mathrm{b}}$ All conditions were measured as ever having been told by a doctor/health professional, with the exception of current asthma (currently being diagnosed with asthma), COPD (ever having been diagnosed with emphysema or COPD, or having been diagnosed with chronic bronchitis in the past 12 months) and weak/failing kidneys (having been diagnosed in the past 12 months).

${ }^{\mathrm{C}}$ Covariates included in models (but not shown in table) are the following: sex (1 = male), age group (18-44 y, 45-64 y, $\geq 65 \mathrm{y}$ ), race/ethnicity (Hispanic, nonHispanic white, non-Hispanic black, non-Hispanic Asian, non-Hispanic other race), educational level (less than high school, high school diploma/GED, some college, bachelor's degree or higher), total annual combined family income $(<\$ 24,999, \$ 25,000-\$ 49,999, \$ 50,000-\$ 74,999, \geq \$ 75,000)$, married/cohabitating $(1=$ yes), place of residence (not in an MSA, small MSA, large MSA), health insurance status (private, public, other, uninsured), and employed in the past 12 months (1 $=$ yes).

d Covariates included in models (but not shown in table) are the following: age group (18-44 years, 45-64 years, $\geq 65$ years), race/ethnicity (Hispanic, nonHispanic white, non-Hispanic black, non-Hispanic Asian, non-Hispanic other race), educational level (less than high school, high school diploma/GED, some college, bachelor's degree or higher), total annual combined family income $(<\$ 24,999, \$ 25,000-\$ 49,999, \$ 50,000-\$ 74,999, \geq \$ 75,000)$, married/cohabitating $(1=$ yes), place of residence (not in a MSA, small MSA, large MSA), health insurance status (private, public, other, uninsured), and employed in the past 12 months $(1=$ yes).

(continued on next page)

The opinions expressed by authors contributing to this journal do not necessarily reflect the opinions of the U.S. Department of Health and Human Services, the Public Health Service, the Centers for Disease Control and Prevention, or the authors' affiliated institutions. 
(continued)

Table 3. Logistic Regression of Sexual Orientation and Sociodemographic Characteristics on Selected Diagnosed Chronic Conditions Among Adults, United States, 2013 ${ }^{a}$

\begin{tabular}{|c|c|c|c|c|c|c|}
\hline \multirow[b]{2}{*}{ Condition $^{b}$} & \multicolumn{2}{|l|}{ All Adults ${ }^{c}$} & \multicolumn{2}{|l|}{$M^{d}{ }^{d}$} & \multicolumn{2}{|l|}{ Womend } \\
\hline & AOR $(95 \% \mathrm{Cl})$ & $P$ Value & AOR $(95 \% \mathrm{Cl})$ & $P$ Value & AOR (95\% Cl) & $P$ Value \\
\hline Bisexual & $1.97(1.07-3.60)$ & .03 & $2.44(0.93-6.41)$ & .07 & $1.72(0.82-3.60)$ & .15 \\
\hline \multicolumn{7}{|l|}{ CHD } \\
\hline Straight & 1 [Reference] & - & 1 [Reference] & - & 1 [Reference] & - \\
\hline Gay/lesbian & $0.91(0.52-1.59)$ & .75 & $1.17(0.61-2.24)$ & .63 & $0.54(0.20-1.45)$ & .22 \\
\hline Bisexual & $1.17(0.44-3.10)$ & .76 & $1.71(0.55-5.30)$ & .36 & $0.46(0.06-3.65)$ & .46 \\
\hline
\end{tabular}

Hepatitis

\begin{tabular}{|c|c|c|c|c|c|c|}
\hline Straight & 1 [Reference] & - & 1 [Reference] & - & 1 [Reference] & - \\
\hline Gay/lesbian & $2.16(1.40-3.33)$ & $<.001$ & $2.86(1.74-4.72)$ & $<.001$ & $1.48(0.60-3.66)$ & .40 \\
\hline Bisexual & $2.38(1.20-4.75)$ & .01 & $5.24(2.08-13.21)$ & $<.001$ & $0.86(0.29-2.57)$ & .78 \\
\hline
\end{tabular}

Stroke

\begin{tabular}{|c|c|c|c|c|c|c|}
\hline Straight & 1 [Reference] & - & 1 [Reference] & - & 1 [Reference] & - \\
\hline Gay/lesbian & $0.66(0.31-1.44)$ & .30 & $0.37(0.13-1.09)$ & .07 & $1.17(0.42-3.22)$ & .77 \\
\hline Bisexual & $1.28(0.47-3.47)$ & .63 & $0.27(0.05-1.46)$ & .13 & $1.85(0.62-5.54)$ & .27 \\
\hline \multicolumn{7}{|c|}{ Weak/failing kidneys } \\
\hline Straight & 1 [Reference] & - & 1 [Reference] & - & 1 [Reference] & - \\
\hline Gay/lesbian & $1.18(0.56-2.48)$ & .66 & $1.39(0.59-3.25)$ & .45 & $0.94(0.26-3.46)$ & .93 \\
\hline Bisexual & $1.29(0.40-4.14)$ & .67 & $3.41(0.72-16.22)$ & .12 & $0.47(0.10-2.17)$ & .34 \\
\hline
\end{tabular}

Abbreviations: AOR, adjusted odds ratio; CHD, coronary heart disease; $\mathrm{Cl}$, confidence interval; COPD, chronic obstructive pulmonary disease; GED, general educational development; MSA, metropolitan statistical area.

${ }^{a}$ Estimates generated using the 2013 National Health Interview Survey Sample Adult data file $(n=34,557)$.

${ }^{b}$ All conditions were measured as ever having been told by a doctor/health professional, with the exception of current asthma (currently being diagnosed with asthma), COPD (ever having been diagnosed with emphysema or COPD, or having been diagnosed with chronic bronchitis in the past 12 months) and weak/failing kidneys (having been diagnosed in the past 12 months).

${ }^{\mathrm{C}}$ Covariates included in models (but not shown in table) are the following: sex (1 = male), age group (18-44 y, 45-64 y, $\geq 65 \mathrm{y}$ ), race/ethnicity (Hispanic, nonHispanic white, non-Hispanic black, non-Hispanic Asian, non-Hispanic other race), educational level (less than high school, high school diploma/GED, some college, bachelor's degree or higher), total annual combined family income $(<\$ 24,999, \$ 25,000-\$ 49,999, \$ 50,000-\$ 74,999, \geq \$ 75,000)$, married/cohabitating $(1=$ yes), place of residence (not in an MSA, small MSA, large MSA), health insurance status (private, public, other, uninsured), and employed in the past 12 months (1 $=$ yes).

${ }^{d}$ Covariates included in models (but not shown in table) are the following: age group (18-44 years, 45-64 years, $\geq 65$ years), race/ethnicity (Hispanic, nonHispanic white, non-Hispanic black, non-Hispanic Asian, non-Hispanic other race), educational level (less than high school, high school diploma/GED, some college, bachelor's degree or higher), total annual combined family income $(<24,999, \$ 25,000-\$ 49,999, \$ 50,000-\$ 74,999, \geq \$ 75,000)$, married/cohabitating $(1=$ yes), place of residence (not in a MSA, small MSA, large MSA), health insurance status (private, public, other, uninsured), and employed in the past 12 months $(1=$ yes).

The opinions expressed by authors contributing to this journal do not necessarily reflect the opinions of the U.S. Department of Health and Human Services, the Public Health Service, the Centers for Disease Control and Prevention, or the authors' affiliated institutions. 
Table 4. Age-Adjusted Prevalence of Selected Diagnosed Multiple Chronic Conditions Among Adults, by Sexual Orientation and Sex, United States, 2013a

\begin{tabular}{|c|c|c|c|c|}
\hline \multirow[b]{2}{*}{ Condition $^{b}$} & \multicolumn{4}{|c|}{$\%(95 \% \mathrm{Cl})$} \\
\hline & Total & Gay/Lesbian & Straight & Bisexual \\
\hline \multicolumn{5}{|l|}{ All adults } \\
\hline 0 conditions & $52.7(52.0-53.3)$ & $47.8(42.8-52.7)$ & $52.8(52.2-53.5)$ & $49.4(40.9-58.0)$ \\
\hline 1 condition & $23.5(22.9-24.1)$ & $25.8(21.4-30.9)$ & $23.4(22.8-24.0)$ & $27.5(20.2-36.2)$ \\
\hline 2 or 3 conditions & $19.3(18.8-19.7)$ & $23.0(18.8-27.8)$ & $19.2(18.7-19.7)$ & $15.7(10.4-23.2)$ \\
\hline$\geq 4$ conditions & $4.6(4.3-4.9)$ & $3.5(2.2-5.4)$ & $4.6(4.3-4.9)$ & $7.4(3.6-14.5)^{\mathrm{C}}$ \\
\hline \multicolumn{5}{|l|}{ Men } \\
\hline 0 conditions & $54.1(53.2-55.0)$ & $48.7(42.5-55.1)$ & $54.2(53.3-55.2)$ & $45.6(36.0-55.6)$ \\
\hline 1 condition & $22.9(22.0-23.8)$ & $26.1(20.5-32.5)$ & $22.9(22.0-23.8)$ & $29.7(18.5-44.0)$ \\
\hline 2 or 3 conditions & $18.5(17.7-19.2)$ & $22.1(16.8-28.4)$ & $18.4(17.6-19.1)$ & $15.3(8.6-25.8)$ \\
\hline$\geq 4$ conditions & $4.5(4.1-4.9)$ & $3.1(1.7-5.8)^{c}$ & $4.5(4.1-4.9)$ & $9.4(3.9-21.0)^{\mathrm{C}}$ \\
\hline \multicolumn{5}{|l|}{ Women } \\
\hline 0 conditions & $51.3(50.4-52.2)$ & $46.6(38.7-54.6)$ & $51.4(50.5-52.4)$ & $56.3(43.9-67.9)$ \\
\hline 1 condition & $24.0(23.2-24.8)$ & $25.8(19.6-33.1)$ & $23.9(23.1-24.7)$ & $24.9(17.4-34.4)$ \\
\hline 2 or 3 conditions & $20.0(19.3-20.7)$ & $23.9(18.1-31.0)$ & $20.0(19.3-20.7)$ & $14.1(7.7-24.7)^{\mathrm{C}}$ \\
\hline$\geq 4$ conditions & $4.7(4.3-5.5)$ & $3.8(2.0-7.2)^{\mathrm{c}}$ & $4.7(4.3-5.0)$ & $-d$ \\
\hline
\end{tabular}

Abbreviations: $\mathrm{Cl}$, confidence interval; COPD, chronic obstructive pulmonary disease; $\mathrm{CHD}$, coronary heart disease.

${ }^{a}$ Estimates were generated using the 2013 National Health Interview Survey Sample Adult data file $(n=34,557)$.

$\mathrm{b}$ Ten chronic conditions were included in the study: hypertension, arthritis, diabetes, cancer, current asthma, COPD, CHD, hepatitis, stroke, and weak/failing kidneys. All conditions were measured as ever having been told by a doctor/health professional, with the exception of current asthma (currently being diagnosed with asthma), COPD (ever having been diagnosed with emphysema or COPD, or having been diagnosed with chronic bronchitis in the past 12 months) and weak/failing kidneys (having been diagnosed in the past 12 months). Age-adjustment was to the 2000 US Census projected population using 3 age groups: 18-44 years, $45-64$ years, and $\geq 65$ years.

${ }^{\mathrm{c}}$ Estimates have a relative standard error (RSE) $>30.0 \%$ and $\leq 50.0 \%$ and should be interpreted with caution.

d Estimates have a RSE $>50.0 \%$, are considered unreliable, and are not reported. 